\title{
STUDY OF ACTIVE FARMLAND USE TO SUPPORT AGENT-BASED MODELING OF FOOD DESERTS
}

\author{
Saurabh S. Dhamankar ${ }^{1}$, Leila Hashemi-Beni ${ }^{1 *}$, Lyubov A. Kurkalova ${ }^{1}$, Chyi Lyi Liang ${ }^{1}$, Timothy Mulrooney ${ }^{2}$, Manoj \\ $\mathrm{Jha}^{1}$, Gregory Monty ${ }^{1}$, Haoran Miao ${ }^{1}$ \\ ${ }^{1}$ North Carolina A\&T State University \\ ${ }^{2}$ North Carolina Central University \\ *1hashemibeni@ncat.edu
}

KEY WORDS: Food Desert, Agent-Based Modeling, Land-Use, Spatial Analysis, Temporal Analysis

\begin{abstract}
:
Food desert (FD) is the area that has limited access to affordable and nutritious foods such as fresh fruits, vegetables, and other healthful whole foods. FDs are important socio-economic problems in North Carolina (NC), potentially contributing to obesity in low-income areas. If farmland is available, local vegetable production could potentially help alleviate FDs. However, little is known about land use and land-use transitions (LUTs) in the vicinity of FDs. To fill this knowledge gap, we study the farmland use in three NC counties, Bladen, Guilford and, Rutherford, located in Coastal, Piedmont, and, Mountain regions of the state, respectively. The analysis combines the United States Department of Agriculture (USDA) 2015 FD/NFD delineation of census tracts, and geospatial soil productivity and 2008-2019 land cover data. The understanding of farmland use is expected to contribute to the development of LUT components of FD Agent-Based Models (ABM).
\end{abstract}

\section{INTRODUCTION}

The term "food desert" (FD) was formally introduced to describe areas with limited access to affordable nutritious foods, particularly areas in lower-income neighborhoods. The definition has led to the development of national and regional maps that focus efforts on equity in food access. Recognition of FDs also marks a strategic change in public health approach to obesity prevention (Karpyn et al., 2012). A growing body of research suggests that the suburbanization of food retailers has contributed to the emergence of urban FDs. While more and more largeformat supermarkets are erected on suburban lands, smaller grocers in older central-city neighborhoods seem to be rapidly disappearing, leaving potential FDs in their wake (Larsen and Gilliland, 2008).

United States Department of Agriculture (USDA) has developed an web-based, national mapping tool that pinpoints the location of FDs at the census track level (https://www.ers.usda.gov/dataproducts/food-access-research-atlas/, accessed July 2020). The tool and the corresponding data have been used in multiple studies. For example, Smith et al. (2012) evaluated how recent trends and legislative developments have increased access to fresh and healthy food in New Jersey. In particular, since 2011, the state's legislative acts have allowed nonprofit corporations and associations located in select New Jersey cities to transform vacant properties into gardens for growing fruits and vegetables. The government has lowered the cost of urban agriculture projects by making public land available, tax-free, and thus contributing to alleviation of FD in the select cities. While Smith et al. (2012) focused on vacant urban properties as a source of land for expanding local vegetable production, potentially larger areas could come from farmland, the land use considered in this study.
In this paper, we investigate the use and the potential availability of farmland for vegetable production within three North Carolina (NC) counties, Bladen, Guilford, and, Rutherford. The study areas have been chosen to reflect the within-state geographic and biophysical diversity: the three counties are located in Coastal, Piedmont, and Mountain regions, respectively.

The exploration of the local food production approach to alleviation of FDs requires an understanding of not only land use at a specific point of time, but also land-use change. The change in land use/cover is one of the most profound human-induced alterations of the Earth's system. Land conversion for farming or other productive uses serves human well-being but also causes changes in ecosystem functions. Land use change emerges from the interactions among various components of the coupled human-landscape system, which then feeds back to the subsequent development of those interactions. Accrual of these short-term changes over time and the aggregation of these localized changes over space generate larger-scale emergent patterns of land use transition (LUT) and economic development (Le et al., 2008). Simulation models capturing changes in both space and time have a potential to explain the observed LUTs and to explore the possible future developments in land-use systems.

An ABM is a class of computational models for simulating the actions and interactions of autonomous agents to assess their effects on the system as a whole. An agent-based simulation is most commonly used to model individual decision- making and social and organizational behavior. In an ABM, a simulation environment is composed of agents and rules. Le et al. (2008) discusses the concept and theoretical specification of a multiagent-based model for spatio-temporal simulation of a coupled human landscape system. The authors emphasize that the understanding of the LUT is imperative for understanding the rules of such coupled human landscape systems. 
The social, ecological, and economic nature of ABMs has a strong connection with Geographic Information Systems (GIS). The habitat of an agent and its surrounding environment influence the agent's decision-making, which in turn can influence or change the landscape the agent interacts with. For example, Swetnam et al. (2011) presents a GIS method to interpret qualitatively expressed socio-economic scenarios in quantitative map-based terms. The study builds scenarios using local stakeholders and experts to define how major land cover classes may change under different sets of conditions. The study formalizes spatially explicit rules of changes and presents future land cover maps, which can then be used to model ecosystem services. Such modeling of social agents' interactions over a period of the time, in a spatially referenced environment, provides a powerful tool for policymakers, planners, managers, and the public to understand the outcomes of the simulation.

To quantify the use and the potential availability of farmland for vegetable production, we overlay and analyze several data layers developed by USDA: geospatial soil productivity data, the 20082019 Crop Data Layer (CDL) land cover data, and the 2019 FD/NFD delineation of census tracts. We group all farmland in six broad categories, with the first two categories, vegetables \& produce and berries \& non-tree fruits corresponding to the land use that immediately produces healthful whole foods. The additional four categories correspond to the other farmland uses that could require alternative levels of investment to transition to the first two categories: fallow, hay, single season crops, and double season crops. For each of the county, we conduct spatiotemporal analyses to investigate whether FD and NFD areas differ in the relative importance of the six broad uses of farmland and farmland soil quality. We find significant between-county differences in the relative importance of the six broad uses of farmland. However, we find only limited differences between FD and NFD land use or soil quality within the counties.

This study contributes to the development and testing of LUT rules applied to agent-based economic models, with the ultimate goal of developing an ABM to assess the impacts of alternative FD policy interventions.

\section{METHODOLOGY}

\subsection{Study Area and Data}

The National Agricultural Statistical Service (NASS) of USDA groups counties in each state in Agricultural Statistical Districts by geography, climate, and cropping practices (USDA, 2000). To reflect the natural resources and farmland use diversity of $\mathrm{NC}$, the study counties are selected from three different agricultural statistical districts (ASDs): Southern Coastal (Bladen county), Northern Piedmont (Guilford county), and Western Mountain (Rutherford county) (Figure 1)

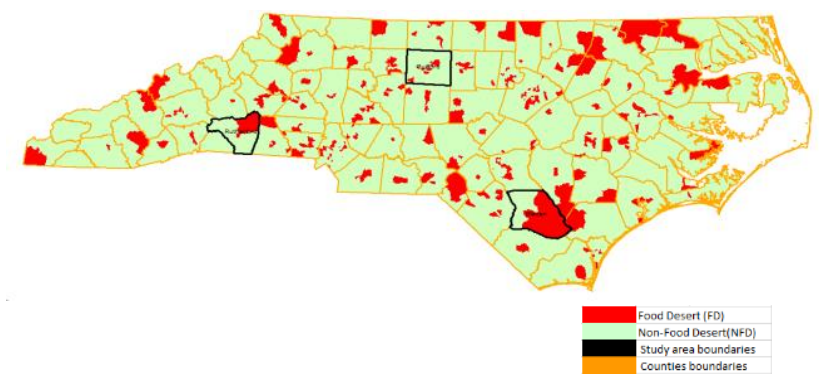

Figure 1. North Carolina food desert census tracts and study areas
Three data sets, all developed and maintained by the USDA, are used in the analysis. The location of FDs comes from the USDA Food Access Research Atlas (https://www.ers.usda.gov/dataproducts/food-access-research-atlas/, accessed July 2020), which provides food access indicators by census tract. We use the latest, 2015 data available, with the FD defined as low-income tract with at least 500 people, or 33 percent of the population, living more than 1 mile (urban areas) or more than 10 miles (rural areas) from the nearest supermarket, supercenter, or large grocery store.

To represent the soils' innate crop productivity, we use the National Commodity Crop Productivity Index (NCCPI) data layer coming from the $30 \mathrm{~m}$ raster produced by the USDA National Resources Conservation Service (USDA/NRCS, 2020). The NCCPI ranks the inherent capability of soils to produce agricultural crops without irrigation on a scale of 0-1 with larger values indicating more productive soils.

The land use data come from the Crop Data Layer (CDL), an annual, raster, geo-referenced, crop-specific land cover data layer with the spatial resolution of 30m (USDA/NASS, 2020). The annual land cover classification includes broad categories such as urban/developed land, forests, and wetlands, and is specifically tailored toward crop identification (Lark et al., 2017). Approximately 70 land uses show in NC layers every year. We use all the yearly layers for which the CDL data are available consecutively for NC, $2008-2019$.

The county data summaries (Table 1) reveal that Bladen has the largest, while Guilford has the lowest share of area in FD.

\begin{tabular}{|l|l|l|}
\hline County & Area (Acres) & $\begin{array}{l}\text { Food Desert } \\
\text { Area (\%) }\end{array}$ \\
\hline Bladen & 537,404 & 64 \\
\hline Guilford & 397,284 & 08 \\
\hline Rutherford & 342,238 & 31 \\
\hline
\end{tabular}

Table 1: Summary statistics

\subsection{Spatial Analysis}

A spatio-temporal analysis has been carried out using ArcGIS by ESRI. The flow chart of spatial analysis is shown in Figure 2. At the initial step, Data Collection, the data are collected from various authentic sites. The FD data comes in a tabular (spreadsheet) format by the census tract. The census tract (CT) map has been downloaded from the U.S. Census Bureau web site (https://www.census.gov/geographies/reference-

maps/2010/geo/2010-census-tract-maps.html, accessed July 2020). The FD map of NC was created using the spatial join of the CT map and the FD data.

The CDL is downloaded from the USDA/NASS (2020). The data for the state of $\mathrm{NC}$ has to be clipped out from the original downloaded map for data processing. For each of the yearly layers, 2008 to 2019, we consider only farmland categories (approximately 50 categories) that represent land uses that are either currently or relatively easily (within a year) could be devoted to production of vegetables and fresh produce. To reduce the total number of farmland categories to a manageable set, we reclassify farmland use in six broad FL categories (Table 2). 


\begin{tabular}{|c|c|c|}
\hline FL category & $\begin{array}{l}\text { FL category } \\
\text { definition }\end{array}$ & $\begin{array}{l}\text { Original } \mathrm{CDL} \\
\text { categories }\end{array}$ \\
\hline $\begin{array}{l}\text { Vegetables \& } \\
\text { produce (VP) }\end{array}$ & $\begin{array}{l}\text { Vegetables and } \\
\text { produce which are } \\
\text { grown as annuals, or as } \\
\text { short-time-span } \\
\text { perennials }\end{array}$ & $\begin{array}{l}42-44, \quad 46, \quad 47, \\
49-54,57, \quad 206- \\
208, \quad 214-216, \\
219, \quad 222, \quad 227, \\
243-248\end{array}$ \\
\hline $\begin{array}{l}\text { Berries \& non- } \\
\text { tree fruits (BF) }\end{array}$ & $\begin{array}{l}\text { Berries and fruits } \\
\text { which are grown as } \\
\text { annuals, or as short- } \\
\text { time-span perennials }\end{array}$ & $\begin{array}{l}48,55,209,213, \\
221,242,250\end{array}$ \\
\hline Fallow $(\mathrm{F})$ & $\begin{array}{l}\text { Land that currently has } \\
\text { no crops on it, but that } \\
\text { could be brought back } \\
\text { to production without } \\
\text { any additional } \\
\text { investment }\end{array}$ & 61 \\
\hline Hay $(\mathrm{H})$ & $\begin{array}{l}\text { Grasses grown as a } \\
\text { source of animal feed }\end{array}$ & $37,37,176$ \\
\hline $\begin{array}{l}\text { Single season } \\
\text { row crops (SC) }\end{array}$ & $\begin{array}{l}\text { Row crops planted in } \\
\text { the spring and } \\
\text { harvested in the fall }\end{array}$ & $\begin{array}{l}1-25,27-35,38- \\
41,45,56,58- \\
60, \quad 205, \quad 224, \\
229,249\end{array}$ \\
\hline $\begin{array}{l}\text { Double } \\
\text { cropped (DC) }\end{array}$ & $\begin{array}{l}\text { Two crops are grown } \\
\text { during the same crop } \\
\text { production year: one } \\
\text { crop is planted in the } \\
\text { fall and harvested in the } \\
\text { spring, and the other } \\
\text { crop planted in the } \\
\text { spring and harvested in } \\
\text { the fall }\end{array}$ & $\begin{array}{l}26, \quad 225, \quad 226, \\
230-241,254\end{array}$ \\
\hline
\end{tabular}

Table 2: Six farmland (FL) categories. Note: The complete list of the original CDL categories is available in USDA/NASS (2020).

The FL data is overlaid with FDP data to obtain the maps and the estimates of the areas. Then results were summaries in the form of charts.

The Soil Productivity Layer (SPL) is downloaded from the USDA/NRCS (2000) and is available in two parts for the state of NC. The two SPL maps were merged to cover the study areas in a single layer, NC SPL. The NC SPL is used in further analysis to estimate the average soil productivity of different areas and classes. The average productivity of farmland categories and/or areas is estimated using a zonal analysis applied to the corresponding categories and/or areas.

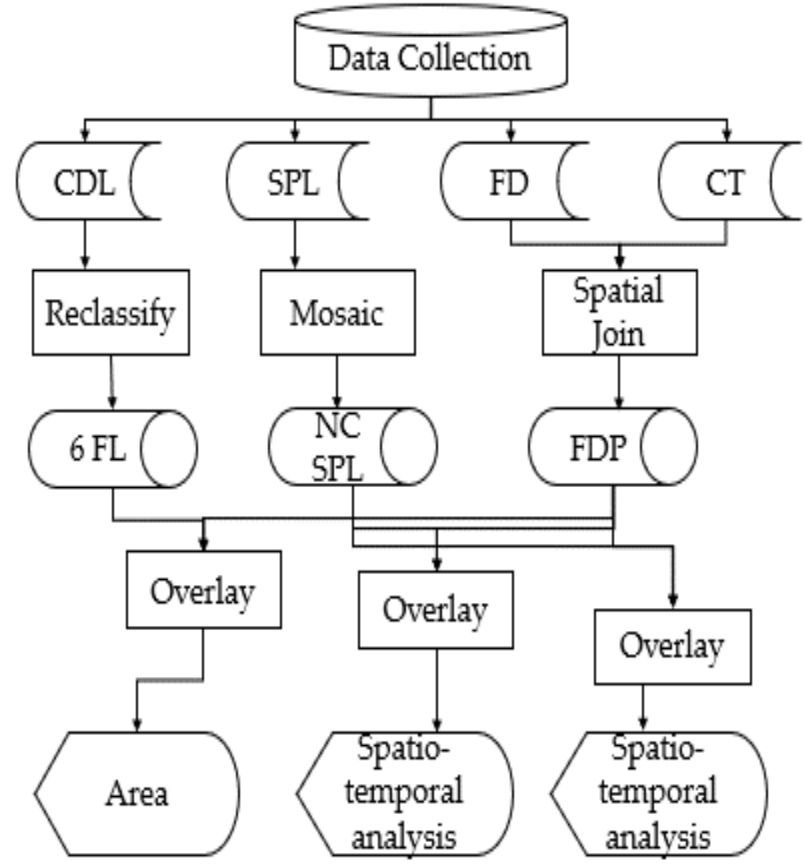

Figure 2. Flow chart of spatial analysis

\section{RESULTS AND DISCUSSION}

We find that the use of the FL is dominated by hay in the Rutherford County, and, to a smaller extent, in Guilford county, while single season crops dominate in Rutherford county (Figure 3 and Figure 4). These differences confirm to prior expectations because the western (Mountain) section of the state has a predictable weather patterns but a short growing season, and hence is not well suited for crop production. The length of the crop-growing season increases eastward, with the Coastal Plain being most suitable part of the state for growing crops (Brown and Vogt, 2015).

Overall, only a small share of farmland is currently under VP and $\mathrm{BF}$, with the largest 2008-2019 average share recorded in Bladen County, barely above $0.2 \%$, (Figure 5 and Figure 6). Because of these small shares, to better present the differences across counties, Figure 6 is focusing exclusively on VP. The climatic conditions suitable for crop production in general seem to be benefiting vegetable and fruit production as well: Bladen County has the highest VP and BF shares among the three study areas. The spatial pattern of farmland use in the county suggests that VP and BF uses are concentrated in only a few spots - the finding that warrants additional investigation.

The patterns of soil productivity (Figure 7) suggest that vegetable and fresh produce production favors a higher quality land in North Carolina: the average NCCPI of VP is approximately the same as that of SC, with both statistics being noticeably higher than those for the other four farmland uses.

The comparison of FD and NFD farmland use (i.e., Figures 3, 4 and 6) does not reveal any notable differences in farmland use inside versus outside of food deserts in the study areas. Nor there appears to be any difference in the average farmland soil productivity between FD and NFD (Figure 8). 


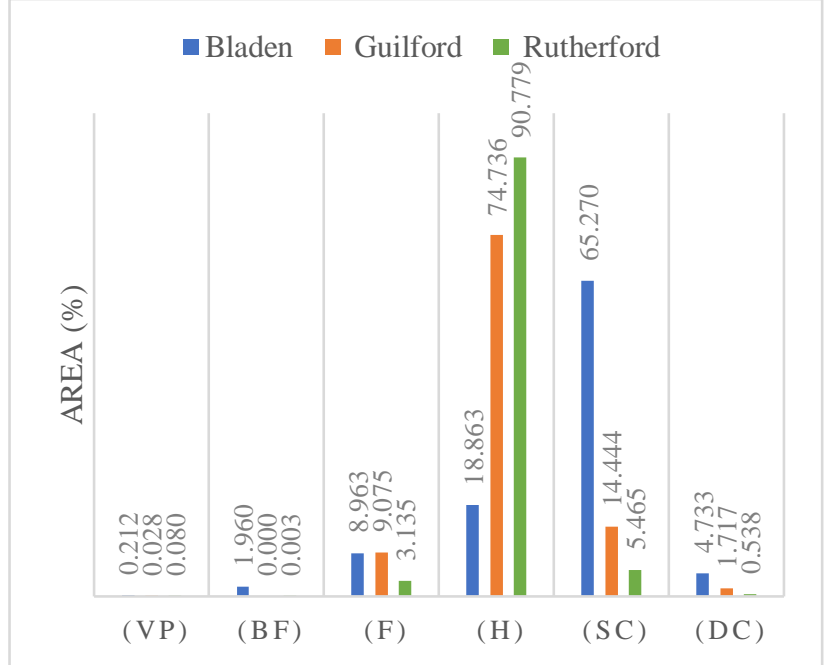

Figure 3. Food deserts: 2008-2019 average shares of the farmland area under alternative uses. Notes: $\mathrm{VP}=$ vegetables \& produce, $\mathrm{BF}=$ berries $\&$ fruits, $\mathrm{F}=$ fallow, $\mathrm{H}=$ hay, $\mathrm{SC}=$ single season, $\mathrm{DC}=$ double season.

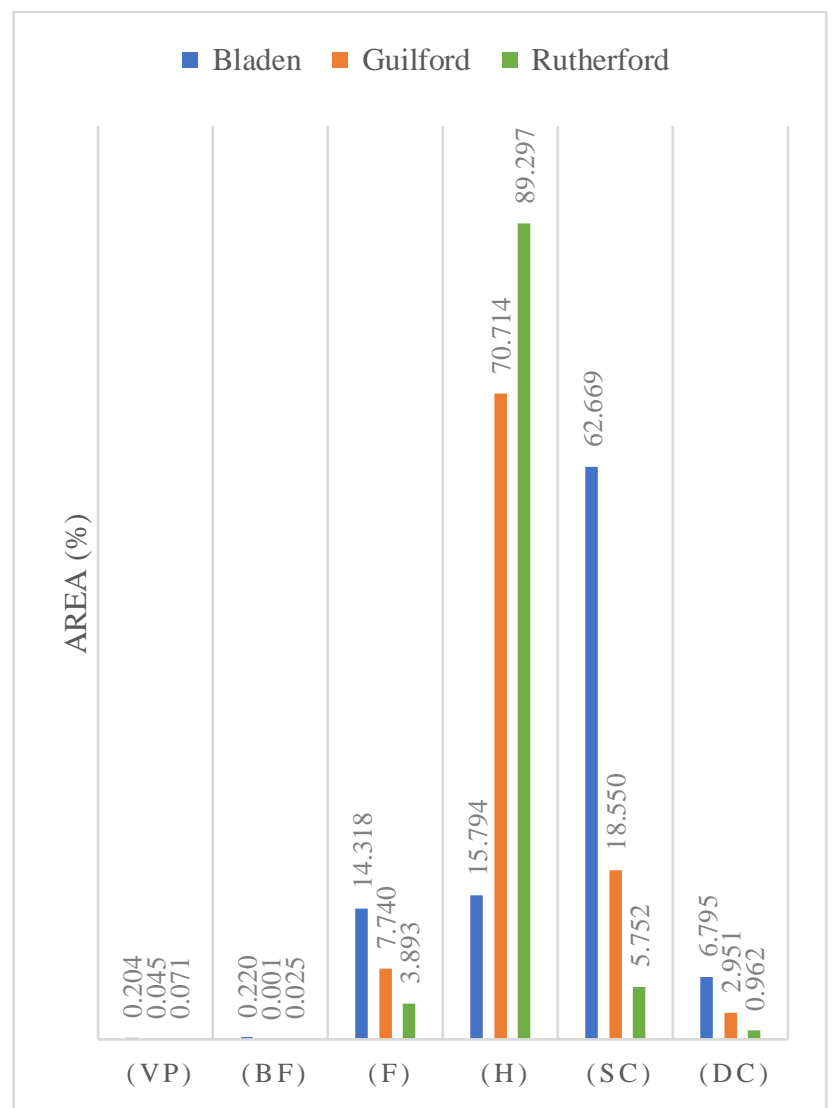

Figure 4. Non-food deserts: 2008-2019 average shares of the farmland area under alternative uses. Notes: $\mathrm{VP}=$ vegetables \& produce, $\mathrm{BF}=$ berries $\&$ fruits, $\mathrm{F}=$ fallow, $\mathrm{H}=$ hay, $\mathrm{SC}=$ single season, $\mathrm{DC}=$ double season.

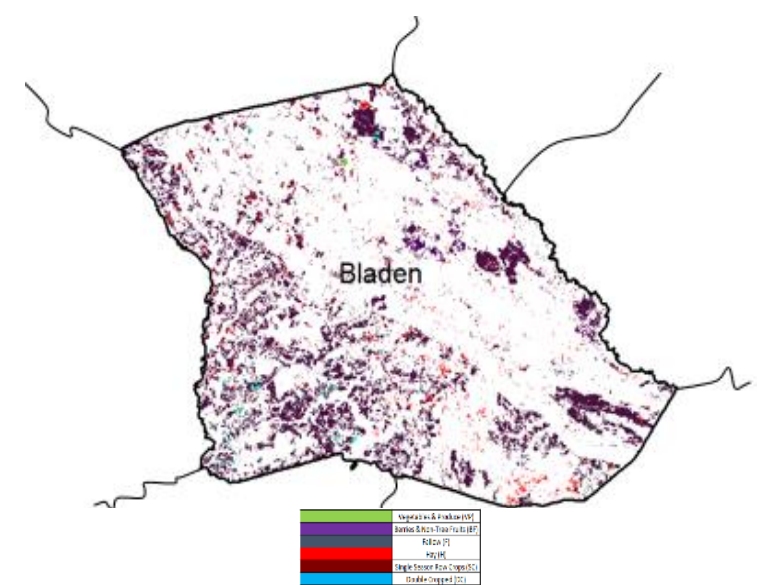

Figure 5. Spatial pattern of farmland uses in Bladen county, 2019.

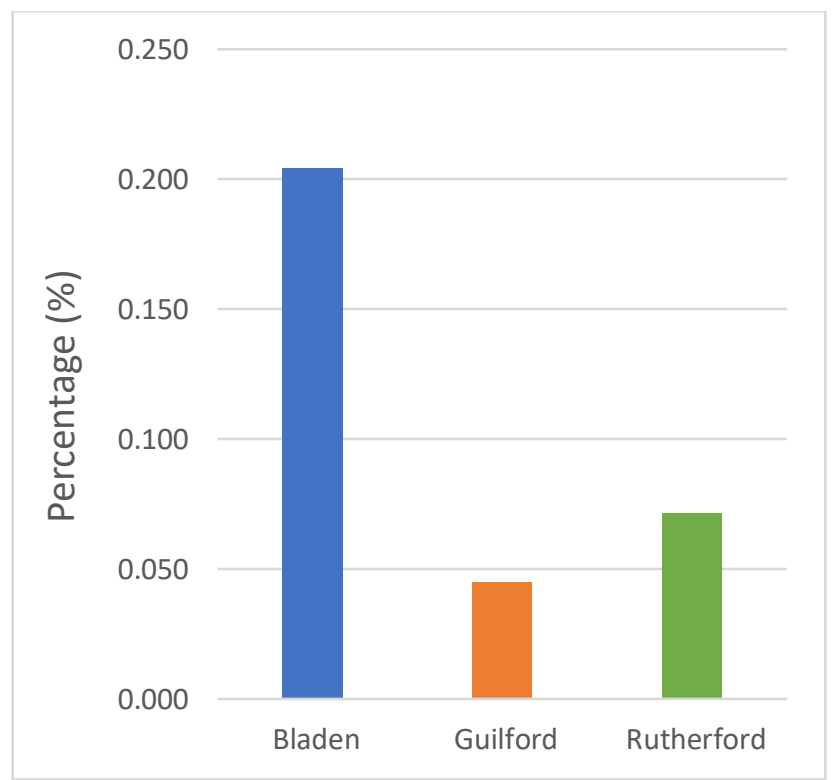

Figure 6. 2008-2019 average shares of the farmland area under VP

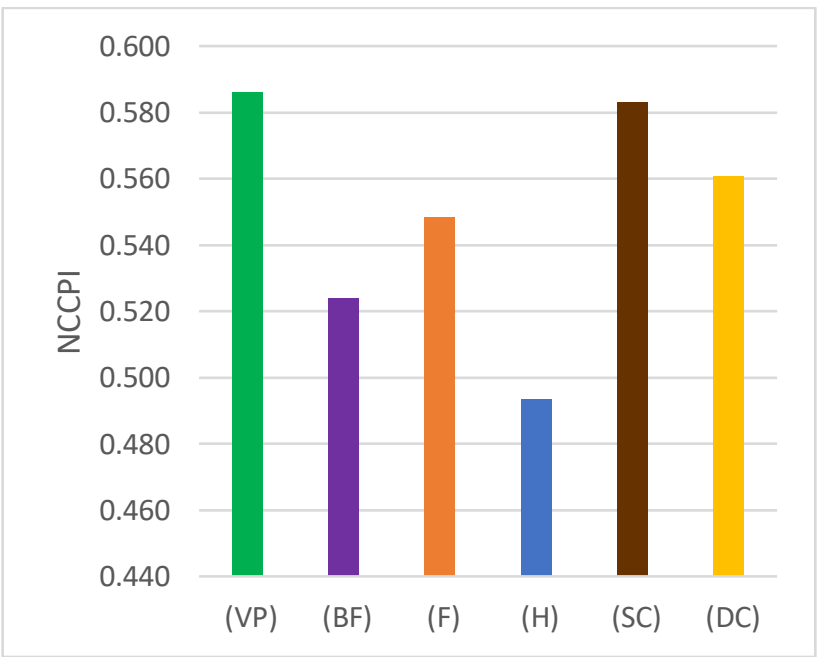

Figure 7. 2008-2019 average productivity of the farmland area under alternative uses. Notes: $\mathrm{VP}=$ vegetables $\&$ produce, $\mathrm{BF}=$ berries \& fruits, $\mathrm{F}=$ fallow, $\mathrm{H}=$ hay, $\mathrm{SC}=$ single season, $\mathrm{DC}=$ double season. 


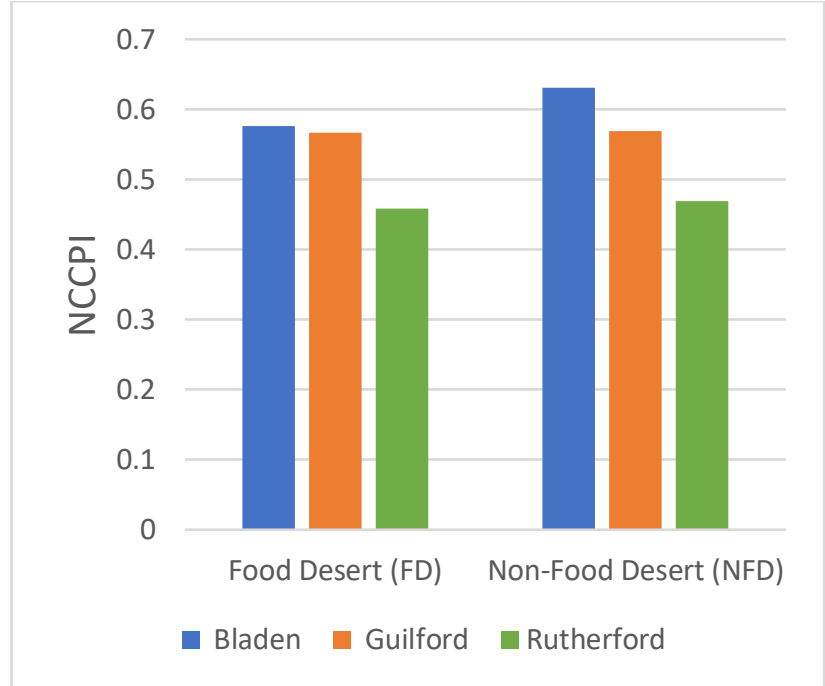

Figure 8. Average productivity of farmland area

\section{CONCLUSIONS}

Twelve years of CDL data, 2008 - 2019, were combined with soil productivity maps to analyze farmland use inside and outside of food deserts in three NC counties. We did not find any noticeable differences in the soil productivity or in the use of farmland between FD and NFD areas. The analysis revealed that highest productivity lands tend to be used to grow VP and SC, while the lower productivity land is double cropped, fallowed, used to grow hay, or berries and non-tree fruits.

The improved understanding of farmland use is expected to contribute to the development of LUT components of FD agentbased models. Our findings lead to two hypotheses to be investigated further. First, our results suggest that the expansion of VP production to fallow, hay, or double-cropped acreage may be limited by soil productivity. In consequence, the transition of farmland to vegetable production might require economic incentives that differ depending on the current land use. Second, there is an indication that vegetable and produce production may be clustered geographically. Future analyses would benefit from investigating which climatic and/or landscape factors contribute to specific geographic patterns of vegetable production in North Carolina.

\section{ACKNOWLEDGEMENT}

This material is based upon research work supported by the National Science Foundation (NSF) under grant No. 1824949

\section{REFERENCES}

Brown, M.J.; Vogt, J.T. North Carolina's forests, 2013. U.S. Department of Agriculture, Southern Research Station, Resource Bulletin SRS-2015. 2015. Ashville, NC.

Karpyn, A., C. Young, and S. Weiss. "Reestablishing Healthy Food Retail: Changing the Landscape of Food Deserts." Child Obes 8.1 (2012): 28-30.

Lark, Tyler J., et al. "Measuring Land-Use and Land-Cover Change Using the U.S. Department of Agriculture's Cropland Data Layer: Cautions and Recommendations." International
Journal of Applied Earth Observation and Geoinformation 62 (2017): 224-35.

Larsen, K., and J. Gilliland. "Mapping the Evolution of 'Food Deserts' in a Canadian City: Supermarket Accessibility in London, Ontario, 1961-2005." Int J Health Geogr 7 (2008): 16.

Le, Q. B., Park, S. J., Vlek, P. L. G., \& Cremers, A. B. (2008). Land-Use Dynamic Simulator (LUDAS): A multi-agent system model for simulating Spatio-temporal dynamics of coupled human-landscape system. I. Structure and theoretical specification. Ecological Informatics, 3(2), 135-153.

Smith, Jim. "Encouraging the Growth of Urban Agriculture in Trenton and Newark through Amendments to the Zoning Codes: A Proven Approach to Addressing the Persistence of Food Deserts." Vermont Journal of Environmental Law 14 (2012): 71 100 .

Swetnam, R. D., et al. "Mapping Socio-Economic Scenarios of Land Cover Change: A Gis Method to Enable Ecosystem Service Modelling." J Environ Manage 92.3 (2011): 563-74.

Tsai, Y., Zia, A., Koliba, C., Bucini, G., Guilbert, J., \& Beckage, B. (2015). An interactive land-use transition agent-based model (ILUTABM): Endogenizing human-environment interactions in the Western Missisquoi Watershed. Land Use Policy, 49, 161176. doi:https://doi.org/10.1016/j.landusepol.2015.07.008

U.S. Department of Agriculture (USDA). (2000). Farm Resource Regions. USDA Economic Resource Service Agricultural $\begin{array}{llll}\text { Information } & \text { Bulletin } & \text { Number }\end{array}$ https://www.ers.usda.gov/publications/pubdetails/?pubid=42299

U.S. Department of Agriculture, National Agricultural Statistics Service (USDA/NASS) Cropland Data Layer. $\{2020\}$. Published crop-specific data layer [Online]. Available at https://nassgeodata.gmu.edu/CropScape/ (accessed \{May 5, 2018\}; verified \{February 4, 2020\}). USDA-NASS, Washington, DC.

U.S. Department of Agriculture, National Resources Conservation Service (USDA/NRCS). (2000). USA Soils Crop Production [Layer package]. ESRI on ArcGIS Online, URL: https://landscape11.arcgis.com/arcgis/ [July 2020].

Wang, Tong, et al. "Determinants of Motives for Land Use Decisions at the Margins of the Corn Belt." Ecological Economics 134 (2017): 227-37.

Worku, Z., \& Elmar, C. (2016). Identifying Categorical Land Use Transition and Land Degradation in Northwestern Drylands of Ethiopia. Remote Sensing, 8(5), 1-20, DOI:10.3390/rs8050408

Abbreviations: FD, food desert; ABM, agent-based model; ASD, agricultural statistical districts; $\mathrm{BF}$, berries \& non-tree fruits; CDL, cropland data layer; CT, census tract; DC, double season row crops; F, fallow; FL, farmland; GIS, geographical information system; H, hallow; LUT, land-use transition; NASS, national agricultural statistical services; NC, north carolina; NCCPI, national commodity crop productivity index; NFD, nonfood desert; NRCS, national resources conservation services; NSF, national science foundation; SC, single season row crops; SPL, soil productivity layer; USDA, united states department of agriculture; VP, vegetables \& produce. 